\title{
The chemical and isotopic composition of Diavik fibrous diamonds and their microinclusions
}

\author{
Oded Navon ${ }^{1}$, Brooke Matat Jablon ${ }^{1}$, Richard Stern ${ }^{2}$ and Thomas Stachel ${ }^{2}$ \\ 1) Institute of Earth Sciences, The Hebrew University, Jerusalem, Israel, oded.navon@mail.huji.ac.il, \\ bmjablon@gmail.com \\ 2) Department of Earth and Atmospheric Sciences, University of Alberta, Edmonton, AB, Canada. rstern@ualberta.ca \\ tstachel@ualberta.ca
}

We investigate a suite of fibrous diamonds (fibrous coats surrounding a monocrystalline octahedral core and cubes that are fully fibrous) from the Diavik Mine in Canada. The diamonds are opaque due to the presence of many microinclusions. They are 4-6 mm in size and weigh 49-134 mg with average of $104 \mathrm{mg}$ (0.52 carat).

FTIR spectra reveal that the cores carry both A and B centers. In cases where it was possible to record pure spectra of the coats, we detected only A centers.

Electron probe micro analysis (EPMA) of the inclusions in 17 diamonds found saline high-density fluids (HDFs) in ten; one diamond carries high-Mg carbonatitic HDFs; two extend from the saline towards the high-Mg carbonatitic composition and four lie on the low-Mg carbonatitic to silicic array. The saline HDFs are rich in potassium, with average molar $\mathrm{K} /(\mathrm{Na}+\mathrm{K})$ of 0.6 . Their $\mathrm{Cl} /(\mathrm{Na}+\mathrm{K})$ ratio is $\sim 1$. The average composition of the saline $\mathrm{HDF}$ (in wt\%) is: $34.5 \% \mathrm{Cl}, 27.7 \% \mathrm{~K}_{2} \mathrm{O}, 11.0 \% \mathrm{Na}_{2} \mathrm{O}, 8.2 \% \mathrm{BaO}, 7.5 \% \mathrm{CaO}$, 7.2\% FeO, $5.7 \% \mathrm{MgO}, 2.8 \% \mathrm{SiO}_{2}, 1.4 \% \mathrm{Al}_{2} \mathrm{O}_{3}$ and $1.3 \% \mathrm{P}_{2} \mathrm{O}_{5}$. The average $\mathrm{Mg \#}$ of the saline fluids is 58 and it increases with decreasing $\mathrm{Cl}$ and increasing $\mathrm{Mg}$ and $\mathrm{Ca}$, pointing towards the $\mathrm{Mg \#}$ of the high- $\mathrm{Mg}$ carbonatitic HDF (82). $\mathrm{Ba}$ is enriched in the saline HDFs and $\mathrm{BaO}$ concentration in the saline fluids grows with increasing $\mathrm{Cl}$.

The carbon and nitrogen isotopic composition of the coats and the fibrous cubes falls within the values of fibrous diamonds $\left(\delta^{13} \mathrm{C}:-4\right.$ to $-10 \%, \delta^{15} \mathrm{~N}$ : 0 to $-10 \%$, Cartigny et al., 2014). Most of the diamonds reported here fall in a tighter range: $\delta^{13} \mathrm{C}$ of -6.5 to $-9.0 \%$ and $\delta^{15} \mathrm{~N}$ between -2 and $-4 \%$. One saline diamond falls at $\delta^{13} \mathrm{C}$ and $\delta^{15} \mathrm{~N}$ between -2 and $-4 \%$ and a low-Mg carbonatitic diamond has the same range in $\delta^{13} \mathrm{C}$, but more negative $\delta^{15} \mathrm{~N}(-4$ to -5.5$)$. Even the cores of the coated diamond span a narrow range in $\delta^{13} \mathrm{C}$ (most fall between -4.2 to -5.2$)$, but their $\delta^{15} \mathrm{~N}$ covers a wide range ( +0.3 to -16$)$.

Nitrogen concentrations vary between 700 and 1900 ppm and exhibit a broad correlation with the isotopic ratios, with the higher nitrogen concentrations are associated with heavy carbon and heavy nitrogen compositions.

The composition of the HDF and the isotopic ratios of carbon and nitrogen fall in the range spanned by other Lac de Gras diamonds. We hope that the high resolution data we acquired and the accurate determination of their location relative to the growth zones of the diamond will allow us to follow covariations in fluid chemistry and isotopic composition and to follow the evolution of the fluids and their host diamonds. 